\title{
Corrigendum
}

\section{Three-Year Outcomes in Deep Brain Stimulation for Highly Resistant Obsessive-Compulsive Disorder}

\author{
Benjamin D Greenberg, Donald A Malone, Gerhard M Friehs, Ali R Rezai, Cynthia S Kubu, \\ Paul F Malloy, Stephen P Salloway, Michael S Okun, Wayne K Goodman and Steven A Rasmussen
}

Neuropsychopharmacology (2006) 31, 2394. doi:I0.1038/sj.npp. I 301201

Correction to: Neuropsychopharmacology (2006) 31, 2384-2393. doi:10.1038/sj.npp.1301165

In addition to the research support from Medtronic Inc. already noted, the authors wish to also acknowledge that three of them (BDG; DAM; SAR) were unpaid consultants to
Medtronic Inc. at the time this manuscript was accepted for publication. ARR is on the speaker's bureau and has received honoraria from Medtronic Inc. Another author (MSO) is a speaker for the Medtronic Focus on DBS course with honoraria donated to the University of Florida Foundation. 